\title{
Inmunización feto materna contra antígenos de HLA en mujeres de una población paraguaya
}

\author{
Fernanda Prieto Casal iD, Claudia Cabañas Gadea iD, Sonia Figueredo López (iD) \\ Verónica Villagra Carrón iD \\ ${ }^{1}$ Ministerio de Salud Pública y Bienestar Social, Laboratorio Central de Salud Pública, \\ Departamento de Inmunología. Asunción, Paraguay
}

Cómo referenciar este artículo/

How to reference this article:

\begin{abstract}
Prieto Casal F, Cabañas Gadea C, Figueredo López S, Villagra Carrón V. Inmunización feto materna contra antígenos de HLA en mujeres de una población paraguaya. Mem. Inst. Investig. Cienc. Salud. 2021; 19(1): 48-57
\end{abstract}

\section{RE S U M E N}

El embarazo es la única causa natural de inmunización contra el sistema de Antígenos Leucocitarios Humano (HLA). Durante la gestación hay paso de leucocitos fetales a través de la placenta, lo que puede desencadenar en la madre una respuesta inmunológica contra los antígenos HLA fetales de origen paterno, con la consecuente producción de anticuerpos. El objetivo del estudio fue conocer la prevalencia de sensibilización a antígenos HLA inducida por embarazos en mujeres paraguayas y estudiar las características y especificidades de los anticuerpos encontrados. Realizamos un estudio descriptivo, prospectivo, de corte transversal de 319 mujeres paraguayas, que acudieron al Laboratorio Central de Salud Pública entre abril de 2017 y abril de 2018 utilizando la tecnología LUMINEX para la detección de anticuerpos antiHLA. Se encontraron anticuerpos anti-HLA en $46 \%$ de las mujeres multíparas. Se detectaron anticuerpos contra todos los antígenos testados. La gran mayoría de los sueros resultaron ser poliespecíficos. Concluimos que al aumentar el número de gestas no solo aumenta la probabilidad de una mujer de desarrollar anticuerpos antiHLA, sino que también parece aumentar la cantidad de especificidades desarrolladas y el título de los anticuerpos.

Palabras clave: anticuerpos anti-HLA, aloinmunización fetomaterna, respuesta inmune, embarazo.

\section{Fetomaternal immunization against HLA antigens in women from a Paraguayan population}

\begin{abstract}
Pregnancy is the only natural cause of immunization against the Human Leukocyte Antigen (HLA) system. During pregnancy, fetal leukocytes pass through the placenta, which can trigger an immunological response in the mother against the fetus paternal HLA antigens, with the consequent production of antibodies. The objective of this study was to determine the prevalence of pregnancy-induced HLA antigen sensitization in Paraguayan women and to study the characteristics and specificities of the antibodies found. We conducted a descriptive, prospective, cross-sectional study of 319 Paraguayan women, who attended the Central Laboratory of Public Health between April 2017 and April 2018 using LUMINEX technology to detect anti-HLA antibodies. We found anti-HLA antibodies in $46 \%$ of multiparous women. Antibodies against all tested antigens were detected. The vast majority of the sera exhibited multiple specificities. We conclude that increasing the number of gestations not only
\end{abstract}

Fecha de recepción: Febrero 2021. Fecha de aceptación: Abril 2021

*Autor correspondiente: Fernanda Prieto. Laboratorio Central de Salud Pública. Dpto. de Inmunología. Av. Venezuela casi Tte. Escurra. Asunción, Paraguay. Teléfono: 595984327381

Email: fprietolab@gmail.com 
increases a woman's likelihood of developing anti-HLA antibodies, but it also appears to increase the number of developed specificities and titers of antibodies.

Keywords: anti-HLA antibodies; fetomaternal alloimmunization; immune response; pregnancy.

\section{INTRODUCCIÓN}

La presencia de anticuerpos anti-HLA en suero del paciente previo a un trasplante de órganos se ha asociado con una alta tasa de rechazo hiperagudo, rechazo mediado por anticuerpos (RMA) y con una alta probabilidad de pérdida del injerto ${ }^{(1-3)}$. El rechazo mediado por anticuerpos anti-HLA es actualmente reconocido como uno de los retos más importantes en el campo del trasplante renal y en menor grado en el trasplante de otros órganos sólidos como páncreas, corazón e hígado ${ }^{(4-13)}$. La aloinmunización anti-HLA requiere de un estímulo antigénico previo y el mismo se puede producir durante el embarazo, por transfusiones sanguíneas, $y / o$ por trasplantes previos ${ }^{(14-17)}$. El embarazo es la única causa natural de inmunización antiHLA. Durante la gestación hay paso de leucocitos fetales a través de la placenta, que al ponerse en contacto con el sistema inmune materno puede inducir en esta una respuesta inmune contra los antígenos HLA fetales de origen paterno, con la consecuente producción de anticuerpos. Aunque dichos anticuerpos no tienen un impacto deletéreo sobre el feto, si lo tienen en el contexto del trasplante de órganos ${ }^{(17-20)}$.

Estudios realizados en mujeres multíparas reportan la presencia de anticuerpos anti-HLA en un 10 a $30 \%$ de ellas ${ }^{(21-24)}$. Sin embargo, en una investigación realizada, en el año 1987, en mujeres multíparas paraguayas, se observó que la prevalencia de estos anticuerpos fue del $47 \%{ }^{(25)}$. Por otra parte, en nuestro laboratorio, hemos observado que el $69 \%$ de las mujeres multíparas en lista de espera para trasplante renal presentaban anticuerpos anti-HLA ${ }^{(26,27)}$.

Cabe destacar que la mayoría de los estudios anteriormente mencionados obtuvieron datos mediante el uso de técnicas de menor sensibilidad y especificidad que las actuales. La técnica clásica para detectar anticuerpos fue la Citotoxicidad Dependiente del Complemento (CDC), posteriormente alrededor del año 1990 se realizaba la detección de anticuerpos anti-HLA utilizando el Ensayo Inmuno Absorbente Ligado a Enzimas (ELISA) que era más específica que la CDC. Y finalmente, desde aproximadamente 20 años, se introdujo la tecnología Luminex® que utiliza moléculas HLA simples recombinantes que permite la detección, además de la caracterización de los anticuerpos anti-HLA con mayor sensibilidad, rapidez y especificidad que las anteriores ${ }^{(28-31)}$.

A la luz de estos avances y a la incorporación de la tecnología Luminex ${ }^{\circledR}$ en el Laboratorio Central de Salud Pública en el año 2017, se propuso un proyecto, con el objetivo de conocer la prevalencia de sensibilización a antígenos HLA inducida por embarazos en mujeres paraguayas y estudiar las características y especificidades de los anticuerpos encontrados.

\section{MATERIALES Y MÉTODOS}

Estudio descriptivo, prospectivo, de corte transversal de 319 mujeres paraguayas, que acudieron al Laboratorio Central de Salud Pública entre abril de 2017 y abril de 2018.

Se utilizaron como criterios de exclusión antecedentes de transfusiones sanguíneas, antecedentes de trasplante alogénico y primer trimestre de embarazo.

Para la recolección de datos cada paciente fue informado de los objetivos del estudio, firmó un consentimiento informado y completó una encuesta para obtener datos de edad, procedencia y antecedentes obstétricos (trimestre de embarazo si correspondía, número de embarazos, número de abortos, tiempo trascurrido desde el último embarazo, número de padres biológicos).

La muestra consistía en $3-5 \mathrm{~mL}$ de sangre extraída por punción venosa periférica y colectada en un tubo sin anticoagulante. Suero separado por centrifugación a 1500 rpm por 10 minutos, alicuotado y almacenado a $-80^{\circ} \mathrm{C}$, hasta su procesamiento. 
Para la detección de anticuerpos anti-HLA se utilizó la plataforma LUMINEX, adaptación de la citometría de flujo estándar que utiliza microperlas fluorescentes recubiertas de antígenos HLA. Primeramente, a todas las muestras se realizó la prueba de cribaje de anticuerpos anti-HLA de Clase I y II utilizando el reactivo LIFECODES LifeScreen Deluxe de IMMUCOR de acuerdo con las instrucciones del fabricante. Para la identificación de los anticuerpos de las muestras positivas se utilizaron los kits de Antígeno Aislado (Single Antigen) LIFECODES LSA Class I y LIFECODES LSA Class II de IMMUCOR siguiendo las instrucciones del fabricante. Los resultados se interpretaron con ayuda del programa "MATCH IT: Antibody Software".

Para hallar cPRA (calculated Panel Reactive Antibodies) se utilizó la calculadora de la página web de la Organización Nacional de Procuración y Trasplante (UNOS), del Ministerio de Salud de los Estados Unidos.

Para el análisis estadístico se tuvo en cuenta el número de embarazos efectivos (número de embarazos - número de abortos). Las muestras fueron distribuidas en 6 grupos de tratamiento. Grupo 0: mujeres sin historial de embarazo (grupo control); Grupo 1: mujeres con antecedente de un (1) embarazo; Grupo 2: mujeres con dos (2) embarazos; Grupo 3: mujeres con tres (3) embarazos; Grupo 4: mujeres con cuatro (4) embarazos; Grupo 5: mujeres con cinco (5) o más embarazos.

Los datos de las encuestas y los obtenidos de los análisis de anticuerpos se introdujeron en una planilla y se analizaron utilizando herramientas de estadística descriptiva.

Para evaluar la asociación entre variables se utilizaron tablas de contingencia de dos por dos, test de chi cuadrado y razón de momios (odd radio). Para todas las pruebas de hipótesis se fijó un nivel de significación de $p<0,05$.

\section{Asuntos Éticos}

El protocolo fue revisado y aprobado por el comité de ética (que cuenta con Certificación Internacional FWA Nº FWAOOO20088) de la Institución con Código de Aprobación CEI-LSCP No 60/200615.

\section{RESULTADOS}

Este estudio incluyó a 319 mujeres cuya edad promedio fue de 39 años (rango: 18 a 85 años); el número de embarazos varió entre 0 a 10; el rango de tiempo trascurrido desde la última gestación fue de 0 a 50 años.

De las muestras estudiadas, $101(31.7 \%)$ arrojaron resultados positivos. Un total de $193(60 \%)$ mujeres informaron ser multíparas ( $\geq 2$ embarazos), encontrándose anticuerpos anti-HLA en $46 \%$ de ellas.

La presencia de anticuerpos anti-HLA fue mayor con el número de embarazos. La relación entre estas dos variables resultó ser directa con un valor de $p<0.05$. Así mismo, se estudiaron los valores de CPRA y MFI de los diferentes grupos de tratamiento, observándose que ambos valores aumentan con el número de gestaciones (Tabla 1).

Tabla 1. Sensibilización a antígenos HLA en los diferentes grupos.

\begin{tabular}{lcccccc}
\hline $\begin{array}{l}\text { Número de } \\
\text { embarazos }\end{array}$ & $\begin{array}{c}\mathbf{0} \\
(\mathbf{n = 6 2})\end{array}$ & $\begin{array}{c}\mathbf{1} \\
(\mathbf{n = 6 4 )}\end{array}$ & $\begin{array}{c}\mathbf{2} \\
(\mathbf{n = 5 7 )}\end{array}$ & $\begin{array}{c}\mathbf{3} \\
(\mathbf{n = 6 5})\end{array}$ & $\begin{array}{c}\mathbf{4} \\
(\mathbf{n = 3 3})\end{array}$ & $\begin{array}{c}\geq \mathbf{5} \\
(\mathbf{n = 3 8})\end{array}$ \\
\hline $\begin{array}{l}\text { Presencia de } \\
\text { anticuerpos anti-HLA }\end{array}$ & $\begin{array}{l}3 \% \\
(2)\end{array}$ & $\begin{array}{l}16 \% \\
(10)\end{array}$ & $\begin{array}{c}40 \% \\
(22)\end{array}$ & $\begin{array}{c}45 \% \\
(30)\end{array}$ & $\begin{array}{c}46 \% \\
(15)\end{array}$ & $\begin{array}{c}55 \% \\
(22)\end{array}$ \\
$\begin{array}{l}\text { Razón de Momios } \\
\text { (Odds Ratio) }\end{array}$ & $\begin{array}{c}\text { Grupo } \\
\text { Control }\end{array}$ & 5.5556 & 18.857 & 25.714 & 25.000 & 41.250 \\
$\begin{array}{l}\text { Nivel de Significancia } \\
(\mathbf{p})\end{array}$ & $\begin{array}{c}\text { Grupo } \\
\text { Control }\end{array}$ & 0.0314 & 0.0001 & $\begin{array}{c}<0.000 \\
1\end{array}$ & 0.0001 & $\begin{array}{c}<0.000 \\
1\end{array}$ \\
\hline
\end{tabular}




\begin{tabular}{|c|c|c|c|c|c|c|}
\hline $\begin{array}{l}\text { cPRA promedio de } \\
\text { todas las muestras }\end{array}$ & $1 \%$ & $11 \%$ & $27 \%$ & $32 \%$ & $30 \%$ & $44 \%$ \\
\hline $\begin{array}{l}\text { cPRA promedio de las } \\
\text { muestras positivas }\end{array}$ & $40 \%$ & $70 \%$ & $71 \%$ & $69 \%$ & $65 \%$ & $77 \%$ \\
\hline $\begin{array}{l}\text { Rango de valores de } \\
\text { MFI máximo de cada } \\
\text { muestra positiva }\end{array}$ & $\begin{array}{l}1201- \\
1845\end{array}$ & $\begin{array}{l}1331- \\
12451\end{array}$ & $\begin{array}{l}1208- \\
14645\end{array}$ & $\begin{array}{c}810- \\
20032\end{array}$ & $\begin{array}{l}1162- \\
17817\end{array}$ & $\begin{array}{l}1258- \\
21433\end{array}$ \\
\hline $\begin{array}{l}\text { Promedio de MFI } \\
\text { máximo de muestras } \\
\text { positivas }\end{array}$ & 1523 & 6530 & 6219 & 7507 & 5592 & 9141 \\
\hline
\end{tabular}

Para las mujeres multíparas se evaluó el efecto de la cantidad de padres biológicos sobre el desarrollo de anticuerpos anti-HLA. No se encontró un efecto significativo $(p=0.3732$, odds ratio $=1.3184)$.

Así también, se evaluó el efecto de los abortos sobre el desarrollo de anticuerpos anti-HLA. Se encontró que esta variable afecta directamente a la sensibilización contra dichos antígenos $(p=0.0011$, odds ratio $=2.2877)$.

De las muestras positivas, 34\% presentaban anticuerpos anti-HLA Clase I, 32\% anticuerpos anti-HLA Clase II y $34 \%$ ambas Clases de Anticuerpos.

Se detectaron anticuerpos contra todas las perlas tanto del kit de Antígeno Aislado Clase I como del de Clase II.

El orden de antigenicidad de las moléculas HLA observado fue de $D R>B>A>D Q>D P>C$. (Figura 1 ).

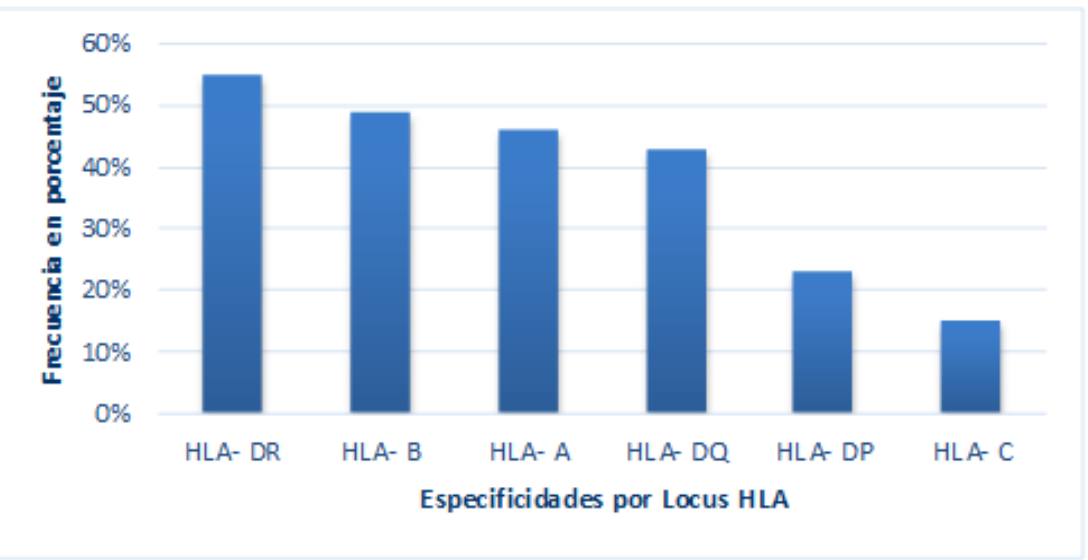

Figura 1. Distribución de Anticuerpos anti-HLA por Locus

Los anticuerpos anti HLA-B y HLA-DR presentaron los valores de MFI más altos (MFI promedio 6183 y 7549 respectivamente), mientras que los valores de MFI de los anticuerpos anti HLA-DP fueron los más bajos (MFI promedio 3489).

\section{Especificidad de los anticuerpos}

De las 101 muestras positivas únicamente 7 presentaron anticuerpos dirigidos contra un solo antígeno HLA (epítopo privado), las demás presentaban múltiples especificidades.

Las especificidades más frecuentes para el Locus HLA-A fueron contra A24, A2, A68, A23 y A69 (Figura 2). 


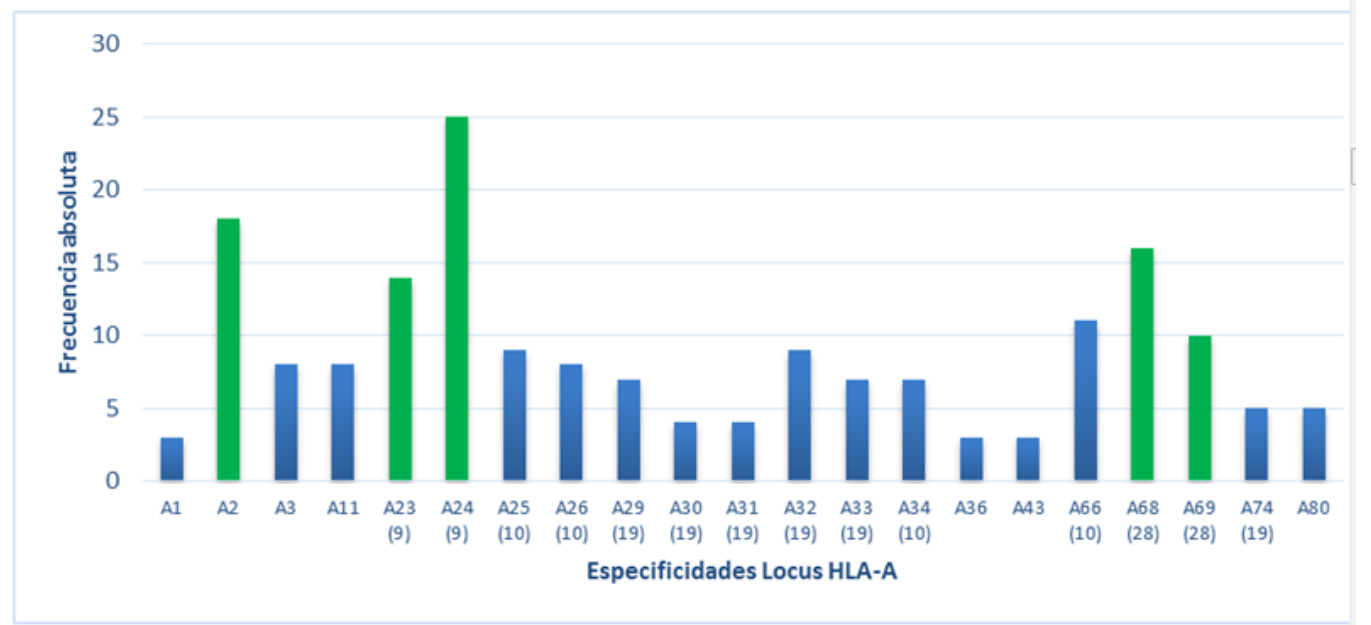

Figura 2. Distribución de Anticuerpos anti HLA-A

Las especificidades más frecuentes encontradas para el Locus HLA-B estaban dirigidas contra los alelos B27, B76, B7, B45, B47 y B60 (Figura 3).

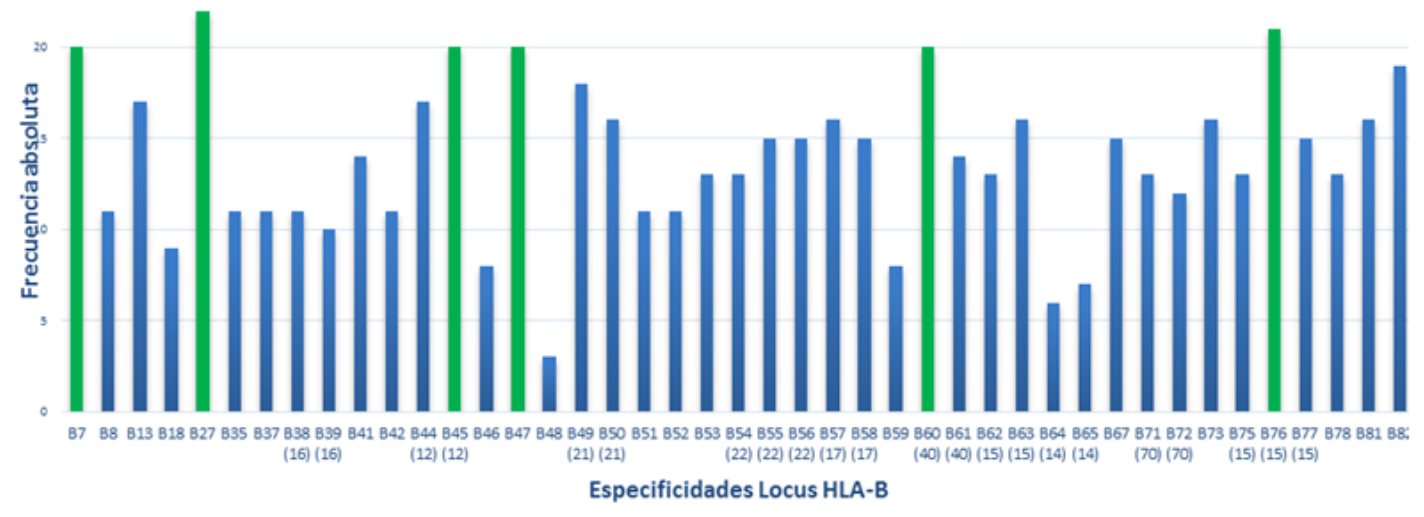

Figura 3. Distribución de Anticuerpos anti HLA-B

La especificidad más frecuente para el Locus HLA-C fue contra HLA-C3 (C9 y C10) y la de menor frecuencia contra HLA-C5.

En el caso del Locus HLA-DR, las especificidades más frecuentes fueron contra el trio DR4, DR7 y DR9 y la pareja DR11 y DR12. Las menos frecuentes fueron contra la pareja DR15 y DR16. (Figura 4).

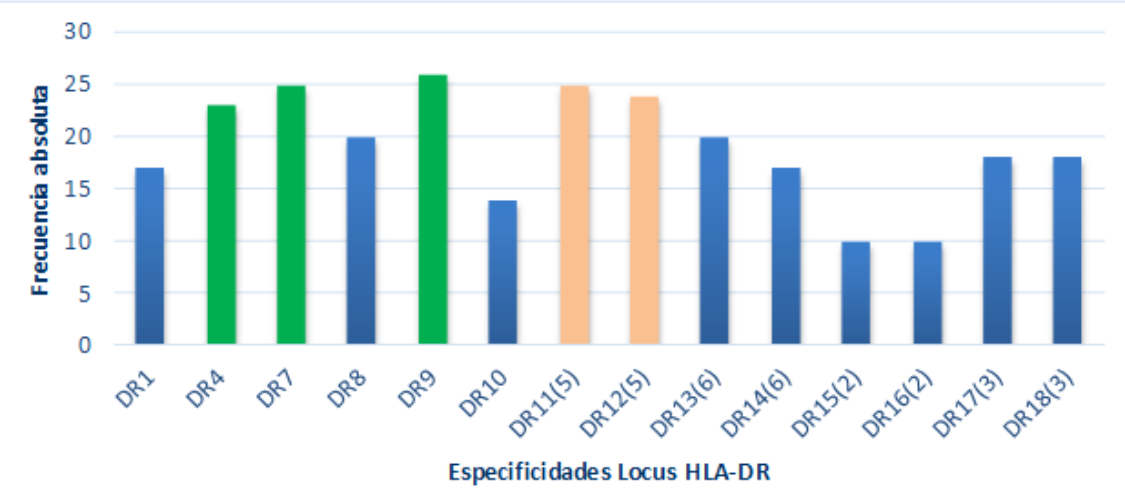

Figura 4. Distribución de Anticuerpos anti HLA-DR 
En cuanto al Locus HLA-DQ, se encontraron anticuerpos contra los 7 antígenos definidos serológicamente como DQ2, DQ4, DQ5, DQ6, DQ7, DQ8, y DQ9 presentes en el kit utilizado. Los anticuerpos contra los antígenos DQ7, DQ8 y DQ9, todos subtipos de DQ3, fueron los más frecuentes (Figura 5).

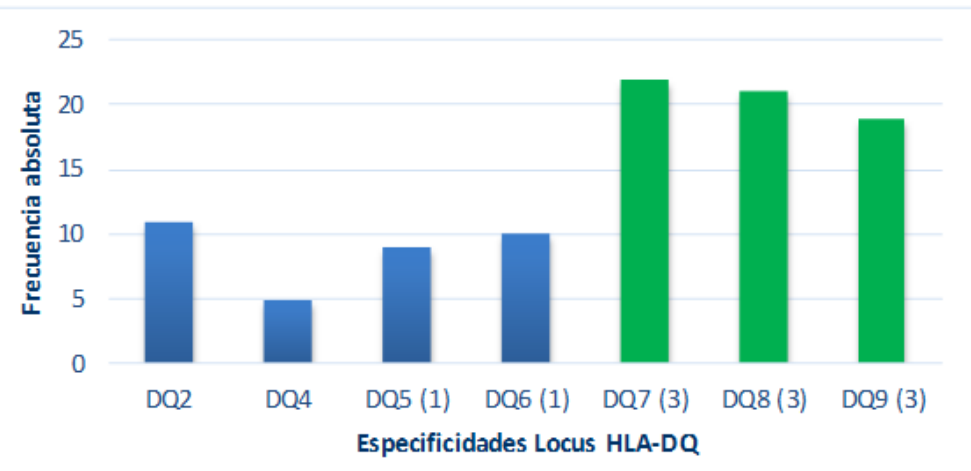

Figura 5. Distribución de Anticuerpos anti HLA-DQ

\section{DISCUSIÓN}

La prevalencia de $46 \%$ de inmunización contra antígenos HLA inducida por embarazos encontrada en este estudio, es consistente con la obtenida hace 34 años atrás en una población de mujeres paraguayas, donde el equipo de Sckell y colaboradores observaron que el $47 \%$ de las mujeres multíparas presentaban anticuerpos anti-HLA ${ }^{(25)}$. Este resultado también es similar al de la Clínica Ginecológica del Hospital de Educación e Investigación de Izmir Tepecik (Turquía), en el cual reportaron que $54 \%$ de las mujeres se sensibilizaron a antígenos HLA a través del embarazo, utilizando la tecnología Luminex ${ }^{(19)}$.

En un estudio realizado en el año 2015 en nuestro laboratorio, reportamos que el $69 \%$ de las mujeres multíparas presentaban anticuerpos anti-HLA, este número aumentado podría deberse a que la población accesible en aquel entonces eran mujeres en lista de espera para trasplante, y la gran mayoría de ellas habían recibido numerosas transfusiones sanguíneas a causa de la enfermedad ${ }^{(26)}$. Gracias a la presente investigación pudimos estudiar aisladamente el efecto del embarazo en la aloinmunización HLA.

Por otro lado, la prevalencia observada en otros países, difiere de la hallada en mujeres paraguayas. Costa Rica reportó que el $12 \%$ de las mujeres multíparas presentaron anticuerpos anti-HLA, mientras que Cuba informó un $20 \%$. Esto podría deberse a que utilizaron métodos de detección de anticuerpos anti-HLA de menor sensibilidad, como la CDC y ELISA respectivamente $e^{(21,23)}$.

Encontramos que existe una relación directa entre el número de embarazos y el porcentaje de sensibilización por antígenos HLA. Diversos autores reportaron este mismo aumento, entre ellos, el estudio de Densmore y colaboradores, cuyo porcentaje de mujeres sensibilizadas por antígenos HLA con 0,1 a 2, >3 embarazos fue 7.8, 14.6 y 26.3 , respectivamente ${ }^{(22)}$, si bien es notorio el incremento, no es el mismo que el observado en nuestro estudio, observar la Tabla 1, también es importante destacar que en nuestro estudio consideramos a las mujeres multíparas a partir de 2 embarazos.

Nuestro resultado también se correlaciona con el reportado en el estudio de Triulzi y colaboradores, donde reclutaron a mujeres de seis bancos de sangre de Estados Unidos, y la prevalencia de anticuerpos anti-HLA también fue incrementando con el número de embarazos: $1.7 \%$ (cero embarazos), $11.2 \%$ (un embarazo), $22.5 \%$ (dos embarazos), $27.5 \%$ (tres embarazos) y $32.2 \%$ (cuatro o más embarazos) $^{(24)}$.

En este sentido es importante destacar que al aumentar el número de gestas no solo aumenta la probabilidad de una mujer de desarrollar anticuerpos, sino que 
también aumenta el porcentaje de cPRA (relacionado a las especificidades de los anticuerpos) y el valor de MFI (relacionado al título de los anticuerpos).

De acuerdo con el presente estudio, las moléculas HLA exhiben diferentes grados de inmunogenicidad. El orden de antigenicidad encontrado fue $D R>B>A>D Q>D P>C$, por lo que correspondería que el puntaje asignado a los pacientes en lista de espera de trasplante renal para un determinado donante cadavérico esté en relación con el grado de match priorizando este mismo orden.

Varios estudios demuestran el alto grado de respuesta inmune que presenta el locus HLA-DR en comparación con los otros loci ${ }^{(32-34)}$. Esto coincide con lo encontrado en este estudio, donde un alto porcentaje de muestras presentaban anticuerpos anti HLA-DR. Consideramos que el sistema de puntaje de adjudicación de riñones debe favorecer el match HLA-DR entre la pareja donante-receptor.

Los anticuerpos anti HLA-B y HLA-A, le siguen en el porcentaje de inmunogenicidad. Este resultado tiene correlación con el grado de polimorfismo que presentan estos dos loci. Según la última actualización del International Immunogenetics (IMGT)/HLA, la cantidad de alelos es la siguiente: HLA-A: 5266, HLAB: 6537, HLA-C: 5140, HLA-DR: 3168, HLA-DQ:1901 ${ }^{(35)}$. Como se puede observar, la cantidad de alelos HLA-B, HLA-A y HLA-C encabezan el número de polimorfismos, sin embargo, sólo el HLA-B y el HLA-A exhiben una alta respuesta inmunológica.

Encontramos que más del $40 \%$ de los pacientes positivos para anticuerpos anti-HLA presentan anticuerpos específicos contra antígenos HLA-DQ, este resultado se corresponde con la inmunogenicidad observada en el estudio de Kaneku y colaboradores, donde el $85 \%$ de los receptores de trasplante de hígado, desarrollaron anticuerpos de novo contra el antígeno HLA-DQ, lo que demuestra la importancia de una tipificación HLA-DQ del donante y el receptor para obtener una prueba cruzada virtual precisa y confiable $e^{(34,36)}$.

Aunque la frecuencia de anticuerpos anti HLA-C no fue elevada, es importante que el laboratorio de Histocompatibilidad considere estos anticuerpos. En caso de identificarse en el receptor anticuerpos anti-HLA-C puede resultar conveniente ampliar la tipificación del donante y el receptor a este locus.

Es interesante resaltar que se han encontrado muy pocos sueros que posean anticuerpos dirigidos contra un solo antígeno HLA. Los anticuerpos desarrollados durante el embarazo generalmente son dirigidos contra epítopos compartidos por varios antígenos HLA denominados CREGS (Cross Reactive Groups), haciendo que este grupo de mujeres presente niveles de cPRA elevado ${ }^{(20,37)}$.

En el presente estudio, los anticuerpos más frecuentes para el Locus $A$ fueron del CREG 2C, dirigidos contra los antígenos A2, A23, A24, A68, A69; para el Locus B del CREG 7C dirigidos contra B7, B27, B47, B60; y para el Locus DR los dirigidos contra el trío DR4, DR7 y DR9. Según lo reportado por Benítez y colaboradores los alelos más frecuentes de la población mestiza paraguaya son el A2, A29; B35, B7, B51; DR2, $\mathrm{DR5}, \mathrm{DR}^{(38)}$. Se esperaría que la frecuencia de los anticuerpos fuera proporcional a la frecuencia de los antígenos de la población, sin embargo, esta correlación no fue encontrada en todos los casos. El estudio de Lucas y colaboradores tampoco encontró correlación entre la frecuencia de antígenos HLA y la frecuencia de anticuerpos en varias especificidades ${ }^{(39)}$, lo cual indicaría que los antígenos de HLA presentan potenciales antigénicos diferentes.

Hemos encontrado sueros con anticuerpos provenientes de mujeres ancianas cuya última gestación fue hace 50 años. Este hallazgo sugiere que la sensibilización HLA producida por los embarazos es muy duradera.

El hecho de que los anticuerpos formados durante el embarazo sean dirigidos contra antígenos HLA del padre, tiene implicancias cuando hablamos de trasplantes vivos entre esposos cuando la mujer es la receptora o cuando los hijos desean donar a sus madres. Frente a esta situación sugerimos que el Crossmatch previo al trasplante sea realizado con la técnica más sensible disponible que es la citometría de flujo.

Actualmente la técnica de Crossmatch por Citometría de Flujo no se realiza en nuestro medio, y aunque gracias a la detección de anticuerpos anti-HLA donante específicos por tecnología Luminex se han evitado muchos trasplantes que podrían 
haber sido un fracaso, es importante que el laboratorio de Histocompatibilidad cuente también con un citómetro de flujo para realizar estudios de Crossmatch en pacientes hipersensibilizados ${ }^{(28-31)}$.

Dado que la sensibilización a antígenos HLA dificulta la búsqueda de un donante de órganos compatible, este estudio demuestra que, entre los pacientes en lista de espera para trasplante, las mujeres multíparas están en desventaja en comparación con los hombres y las mujeres nulíparas ${ }^{(2,16)}$. Esta desventaja debería considerarse en el sistema de puntuación de asignación de órganos provenientes de donantes cadavéricos, otorgando mayor puntaje a los pacientes más sensibilizados, de manera a equilibrar en cierta medida sus posibilidades de trasplante.

\section{AGRADECIMIENTOS}

Al Dr. Robert C. Scott del UPMC Pinnacle - HLA Laboratory (PA, USA), por su contribución al análisis e interpretación de los datos para el trabajo.

Y a todas aquellas mujeres paraguayas que han participado del presente estudio de investigación.

\section{FINANCIAMIENTO}

Este Proyecto fue cofinanciado por el CONACYT (Consejo Nacional de Ciencia y Tecnología, Paraguay) con recursos del FEEI, Proyecto 14-INV-178, del programa PROCIENCIA.

\section{REFERENCIAS BIBLIOGRÁFICAS}

1. Zhu L, Lee P-C, Everly MJ, Terasaki PI. Detailed examination of HLA antibody development on renal allograft failure and function. Clin Transpl. 2008; 171$87 . \quad$ Disponible en: http://www.ncbi.nlm.nih.gov/pubmed/1 9711514

2. Lefaucheur C, Loupy A, Hill GS, Andrade J, Nochy D, Antoine C, et al. Preexisting donor-specific HLA antibodies predict outcome in kidney transplantation. J Am Soc Nephrol. agosto de 2010;21(8):1398-406. DOI: 10.1681/ASN.2009101065

3. Schlaf G, Apel S, Wahle A, Altermann WW. Solid Phase-Based Cross-Matching as Solution for Kidney Allograft Recipients Pretreated with Therapeutic Antibodies. BioMed Research International. 15 de enero de 2015; 2015:e587158. 10.1155/2015/587158.

4. Puttarajappa C, Shapiro R, Tan HP. Antibody-mediated rejection in kidney transplantation: a review. J Transplant. 2012; 2012: $193724 . \quad$ doi: $10.1155 / 2012 / 193724$

5. Hoshino J, Everly MJ, Kaneku H, Ubara Y, Takaichi K, Terasaki PI. Impact of the presence and duration of donor-specific antibodies on renal function. Transplant Proc. febrero de 2014; 46(1):75-80. DOI:

10.1016/j.transproceed.2013.09.032.

6. Zeevi A, Lunz J, Feingold B, Shullo $M$, Bermudez C, Teuteberg J, et al. Persistent strong anti-HLA antibody at high titer is complement binding and associated with increased risk of antibody-mediated rejection in heart transplant recipients. J Heart Lung Transplant. enero de 2013; 32(1):98105. doi:

10.1016/j.healun.2012.09.021.

7. Cantarovich D, De Amicis S, Akl A, Devys A, Vistoli F, Karam G, et al. Posttransplant donor-specific anti-HLA antibodies negatively impact pancreas transplantation outcome. Am J Transplant. diciembre de 2011;11(12):2737-46. doi: 10.1111/j.1600-6143.2011.03729.x..

8. O'Leary JG, Demetris AJ, Friedman LS, Gebel HM, Halloran PF, Kirk AD, et al. The role of donor-specific HLA alloantibodies in liver transplantation. Am J Transplant. abril de 2014;14(4):779-87. doi: 10.1111/ajt.12667

9. Vionnet J, Sempoux C, Pascual $M$, Sánchez-Fueyo A, Colmenero J. Donorspecific antibodies in liver transplantation. Gastroenterol Hepatol. enero de 2020; 43(1): 34-45. doi: 10.1016/j.gastrohep.2019.09.010.

10. Lima $B$, Mendes $M$, Alves $H$. Hypersensitized candidates to kidney transplantation in Portugal Candidatos hipersensibilizados a transplantação renal em Portugal. Port J Nephrol Hypert. 1 de abril de 2013; 27(2).

11. Brito-García A, Gutiérrez-García $F$, Trujillo-Álvarez $Y$, Peña-Fresneda N, Barberia-Torres D, Díaz-Báez $\mathrm{N}$. Anticuerpos anti-HLA en pacientes con insuficiencia renal crónica en espera de trasplante renal. Revista Cubana de 
Hematología, Inmunología y Hemoterapia. septiembre de 2012; 28(3):275-81.

12. Keith DS, Vranic GM. Approach to the Highly Sensitized Kidney Transplant Candidate. Clin J Am Soc Nephrol. 7 de abril de 2016; 11(4):684-93. doi: 10.2215/CJN.05930615.

13. Garces JC, Giusti S, Staffeld-Coit C, Bohorquez $H$, Cohen AJ, Loss GE. Antibody-Mediated Rejection: A Review. Ochsner J. 2017;17(1):46-55

14. Triulzi DJ, Kleinman S, Kakaiya RM, Busch MP, Norris PJ, Steele WR, et al. The effect of previous pregnancy and transfusion on HLA alloimmunization in blood donors: implications for a transfusion-related acute lung injury risk reduction strategy. Transfusion [Internet]. septiembre de 2009 (citado 14 de abril de 2019); 49(9): 1825-35. Disponible en: http://www.ncbi.nlm.nih.gov/pubmed/1 9453983

15. De Clippel D, Baeten $M$, Torfs A, Emonds M-P, Feys HB, Compernolle V, et al. Screening for HLA antibodies in plateletpheresis donors with a history of transfusion or pregnancy. Transfusion (Internet). diciembre de 2014 (citado 16 de abril de 2019); 54(12): 3036-42. Disponible en: http://www.ncbi.nlm.nih.gov/pubmed/2 4863861

16. Scornik JC, Bromberg JS, Norman DJ, Bhanderi M, Gitlin M, Petersen J. An update on the impact of pre-transplant transfusions and allosensitization on time to renal transplant and on allograft survival. BMC Nephrol. 2013; 14: 217.

17. Yang $X$, Zhang $C$, Chen G, Sun C, Li J. Antibodies: The major participants in maternal-fetal interaction: Antibodies in maternal-fetal interaction. J Obstet Gynaecol Res. 2019; 45(1): 39-46.

18. Masson E, Vidal C, Deschamps $M$, Bongain S, Thevenin C, Dupont I, et al. Incidence and risk factors of anti-HLA immunization after pregnancy. Hum Immunol. agosto de 2013;74:946-51.

19. Cerci Gurbuz B, Soyoz M, Ozkale Okyay D, Kilicaslan Ayna T, Pirim I. Comparison of Anti-HLA Antibody Production According to Gestational Periods in Pregnant Women. Transplant Proc. 1 de abril de 2017; 49(3): 464-6.

20. Resse M, Paolillo R, Minucci BP, Cavalca F, Casamassimi A, Napoli C. Epitopespecificities of HLA antibodies: The effect of epitope structure on Luminex technique-dependent antibody reactivity. Hum Immunol. 1 de abril de 2015; 76(4): 297-300.
21. Muñoz CG, González FR, González CE, Guzmán MA. Sensibilización de madres multíparas por antígenos HLA. Rev costarric cienc méd. junio de $1985 ; 6(2): 1-6$.

22. Densmore TL, Goodnough LT, Ali $S$, Dynis M, Chaplin H. Prevalence of HLA sensitization in female apheresis donors. Transfusion. enero de 1999; 39(1):103-6.

23. Rodríguez LM, Rodríguez LM, Barrios LMM, García CRU, Elizalde DTC, Monteagudo AC, et al. Identificación de anticuerpos anti-HLA en pacientes en espera de trasplante renal. Rev Cuba Hematol Inmunol y Hemoter (Internet). 15 de enero de 2015 (citado 19 de abril de 2021); 31(2). Disponible en: http://www.revhematologia.sld.cu/inde x.php/hih/article/view/266

24. Triulzi DJ, Kleinman $S$, Kakaiya RM, Busch MP, Norris PJ, Steele WR, et al. The effect of previous pregnancy and transfusion on HLA alloimmunization in blood donors: implications for a transfusion-related acute lung injury risk reduction strategy. Transfusion. septiembre de 2009; 49(9):1825-35. DOI: $10.1111 / \mathrm{j} .1537-$ 2995.2009.02206.x

25. Sckell de Duarte C. Investigación de anticuerpos anti HLA en suero de puerperas. Fac Cienc Méd Asunción. 1987; 19(1/2) (49-67).

26. Prieto $F$, Cabañas C, Villagra V. Características de los pacientes en espera de trasplante renal. Memorias del Inst Investig en Ciencias la Salud. abril de $2015 ; 13(1): 49-57$.

27. Prieto $F$, Cabañas $C$, Villagra V. Monitoreo de anticuerpos anti-HLA en pacientes con insuficiencia renal crónica en lista de espera para trasplante. Rev Nefrol Diálisis y Traspl (Internet). 1 de junio de 2016 (citado 16 de abril de 2019); 36(2):75-81. Disponible en: https://www.revistarenal.org.ar/index.p $\mathrm{hp} / \mathrm{rndt} /$ article/view/61

28. Lachmann $\mathrm{N}$, Todorova $\mathrm{K}$, Schulze $\mathrm{H}$,

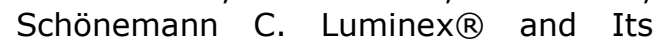
Applications for Solid Organ Transplantation, Hematopoietic Stem Cell Transplantation, and Transfusion. Transfus Med Hemotherapy (Internet). junio de 2013 (citado 14 de abril de 2019);40(3):182-9. Disponible en: http://www.ncbi.nlm.nih.gov/pubmed/2 3922543

29. Süsal C, Opelz G, Morath C. Role and Value of Luminex(®)-Detected HLA Antibodies before and after Kidney Transplantation. Transfus Med Hemother. junio de 2013;40(3):190-5. doi: $10.1159 / 000351314$ 
30. NasrAllah MM, Elalfy MM, Fakhry SA, Rostaing L, Amer I, Elmeseery YA, et al. Impact of Adopting Routine LuminexBased Pretransplant Assessment of HLA Antibodies on Clinical Practice and Outcomes in Kidney Transplantation. Transplant Proc. 2019; 51(7):2241-4. doi:

10.1016/j.transproceed.2019.01.147.

31. Burballa C, Pérez-Saéz MJ, RedondoPachón D, García C, Mir M, AriasCabrales $C$, et al. Luminex screening first vs. direct single antigen bead assays: Different strategies for HLA antibody monitoring after kidney transplantation. Hum Immunol. 2020; 81(6):293-9.

doi: 10.1016/j.humimm.2020.03.003

32. Jucaud $V$. The Immunogenicity of HLA Class II Mismatches: The Predicted Presentation of Nonself Allo-HLADerived Peptide by the HLA-DR Phenotype of the Recipient Is Associated with the Formation of DSA. J Immunol Res. 2017; 2017.

33. Dankers MKA, Roelen DL, Nagelkerke NJD, De Lange P, Persijn GG, Doxiadis IIN, et al. The HLA-DR phenotype of the responder is predictive of humoral response against HLA class I antigens. Hum Immunol 2004; 65(1):13-9.

34. Wiebe C, Kosmoliaptsis V, Pochinco D, Gibson IW, Ho J, Birk PE, et al. HLA DR / DQ molecular mismatch: A prognostic biomarker for primary alloimmunity. Am J Transplant. junio de 2019;19(6):1708-19.

doi: 10.1111/ajt.15177

35. Robinson J, Barker DJ, Georgiou X, Cooper MA, Flicek P, Marsh SGE. IPD-
IMGT/HLA Database. Nucleic Acids Res (Internet). 1 de enero de 2020 (citado 20 de abril de 2021); 48 (D1): D948$55 . \quad$ Disponible en: https://academic.oup.com/nar/article/4 8/D1/D948/5610347

36. Kaneku H, O'Leary JG, Banuelos N, Jennings LW, Susskind BM, Klintmalm GB, et al. De Novo Donor-Specific HLA Antibodies Decrease Patient and Graft Survival in Liver Transplant Recipients. Am J Transplant (Internet). 1 de junio de 2013 (citado 20 de abril de 2021); 13(6):1541-8. Disponible en: 10.1111/ajt. 12212

37. Tambur AR, Claas FHJ. HLA Epitopes as Viewed by Antibodies: What Is it All About? Am J Transplant (Internet). 1 de mayo de 2015 (citado 22 de abril de 2021); 15(5):1148-54. Disponible en: 10.1111/ajt.13192

38. Benitez $O$, Busson $M$, Charron $D$, Loiseau $P$. HLA polymorphism in a Guarani-Indian population from Paraguay and its usefulness for the Hispano-Indian admixture study in Paraguay. Int J Immunogenet (Internet). 1 de febrero de 2011 (citado 22 de abril de 2021); 38(1): 7-11. Disponible en: $10.1111 / \mathrm{j} .1744-$ 313X.2010.00959.x

39. Lucas DP, Leffell MS, Zachary AA. Differences in immunogenicity of HLA antigens and the impact of crossreactivity on the humoral response. Transplantation. enero de 2015;99(1):77-85. doi: 10.1097/TP.0000000000000355 